\title{
The association between gender and tooth loss in a small rural population of South Africa
}

\author{
Charlene W. J. Africa ${ }^{1, *}$, Jairam Reddy ${ }^{2}$ \\ ${ }^{1}$ Department of Medical Biosciences, University of the Western Cape,Cape Town, South Africa \\ ${ }^{2}$ Director, International Leadership Institute, United Nations University, Jordan
}

\section{Email adress:}

cafrica@uwc.ac.za (C. W. J. Africa)

\section{To cite this article:}

Charlene W. J. Africa, Jairam Reddy. The Association between Gender and Tooth Loss in A Small Rural Population of South Africa. Science Journal of Clinical Medicine. Vol. 2, No. 1, 2013, pp. 8-13. doi: 10.11648/j.sjcm.20130201.12

\begin{abstract}
Periodontal disease, which attacks the gums and supporting structures of the tooth, is one of the major causes of tooth loss in adults. Few studies on general well-being have compared the differences in oral health between men and women with studies from Europe and USA reporting that there are more edentulous women than men.Among the many factors contributing to tooth loss are poverty, availability and accessibility to dental and other health care as well as cultural traditions. This study examined a population living in a high fluoride area near Cape Town. This isolated community has until recently been unexposed to the diets and habits of the western world and have inter-married for decades. The results of this study indicated that although women had better oral hygiene habits than men, tooth loss was associated with age rather than gender.
\end{abstract}

Keywords: Tooth Loss, Gender Differences, Oral Health, Periodontal Disease

\section{Introduction}

It is believed that the general health and well-being of a population may be reflected in the oral health status of its women [1].Poor oral health may lead to tooth loss and impair the systemic health of an individual. It may also impact on one's self image, [2], employment opportunities and earnings [3], [4].The major causes of tooth loss include trauma, dental caries and periodontal disease [5]- [10], with associated risk factors such as smoking[11]-[13], consumption of alcohol [12], [14], age [15]-[18], gender [11], [19][21], and socioeconomic status [11], [12], [14], [19][23].However, few natural surveys report on gender differences in their research findings and those that do, often show disparities. Some studies have indicated that there is a higher prevalence of tooth loss in women [18], [24]-[26], others showed a higher prevalence in men [27], [28], while still others showed no significant relationship with gender [19], [23], [27].

Tooth loss due to caries is on the decline due to fluoridation of water supplies, awareness programmes and access to adequate dental care.However, periodontal disease, a disease which attacks the gingiva and supporting structures of the teeth, remains prevalent due to dental plaque accumulations along the gingival margin. Women, because of the shifts in oestrogen and progesterone levels throughout their life cycle, are considered to be more susceptible to periodontal disease than men. [29]. This not only places the women at greater risk for tooth loss than men, but may inpact on other aspects of their health such as coronary heart disease [30],[31] stroke [32], diabetes mellitus [33] and delivery of pre-term low birth weight infants [34],[35]who, in turn, are predisposed to respiratory, heart and liver problems.

Prevalence of tooth loss has been reported to be greater in rural than urban areas. Samples from a population residing in a remote rural area near Cape Town, South Africa, were examined by darkfield microscopy for bacterial morphotypes indicative of periodontal diseaseand were found to have a low prevalence of caries and mild "contained" gingivitis on clinical examination [36]. This was attributed to the high fluoride content $(>2 \mathrm{ppm})$ of their water.Since gender was not factored into the analysis of the data generated from this earlier study, the objective of the present study was to re-examine their data and attempt to establish whether the risk for tooth loss due to periodontal diseasemay be gender- specific in this population.

\section{Materials and Methods}

\subsection{Subject Selection}


Thirty-nine sites from 20 males and 138 sites from 68 females constituted the research sample. Details of the subject population are described in a previous study [37]. The mesial aspect of the upper right premolar (hereafter referred to as 16) and lower central incisor (hereafter referred to as 41) were examined in each patient. The ages of the sampled population ranged from 15 to 75 years.Subjects were selected at random and the study complied with the recommendations of the Declaration of Helsinki. Only totally edentulous subjects were excluded from the study.

The clinical parameters commonly used to diagnose periodontal disease include plaque index (PI), gingival index (GI), probable pocket depth (PD) and loss of attachment (LA). These were measured as follows: PI was scored between $0-3$ depending on the amount of plaque present. $0=$ no plaque in the gingival area, $1=$ a thin film of plaque not visible to the naked eye, $2=$ moderate accumulation of plaque visible to the naked eye, $3=$ abundance of plaque on the tooth surface[38].GI was scored from $0-3$ as follows:0= normal gingiva, $1=$ mild inflammation, slight change, no bleeding, $2=$ moderate inflammation, bleeding on probing, $3=$ severe inflammation, spontaneous bleeding and ulceration [39]. A Michigan type periodontal probe was used to measure PD from the gingival margin to the base of the pocket, while LA was measured from the cemento-enamel junction to the base of the pocket.

\subsection{Statistical Analyses}

Multiple regression analysis was used to establish whether gender or age would increase the risk for tooth loss due to periodontal disease.

\section{Results}

Whether the results were reported per site $(16,41)$ or per subject $(16+41)$, females showed a lower plaque index score than males (Fig. 1A).The same was noted for GI (Fig.1B) and LA (Fig.1C). However, these differences were not significantly different for PI, although the differences for GI and LA showed significance at the 5\% level (Table 1). $\mathrm{PD}$, on the other hand, revealed differences in the 16 and 41 sites for males and females with females showing significantly lower PD scores in the 16 site only (Fig. 1D and Table 1).

Table 1. Comparison of Clinical Indices In Males and Females.

\begin{tabular}{llll}
\hline & \multicolumn{2}{l}{ Tooth Site } & \\
\cline { 2 - 4 } Clinical Index & 16 & 41 & $16+41$ \\
\hline Plaque Index & $\mathrm{p}=0.059$ & $\mathrm{p}=0.169$ & $\mathrm{p}=0.054$ \\
Gingival Index & $\mathrm{p}<0.001^{*}$ & $\mathrm{p}=0.018^{*}$ & $\mathrm{p}=0.008^{*}$ \\
Loss of Attachment & $\mathrm{p}<0.001^{*}$ & $\mathrm{p}=0.968$ & $\mathrm{p}=0.031^{*}$ \\
Probing Depth & $\mathrm{p}<0.001^{*}$ & $\mathrm{p}=0.501$ & $\mathrm{p}=0.070$ \\
\hline
\end{tabular}

*Significant at $5 \%$ level ; $16=$ Upper right premolar ; $41=$ lower central incisor.
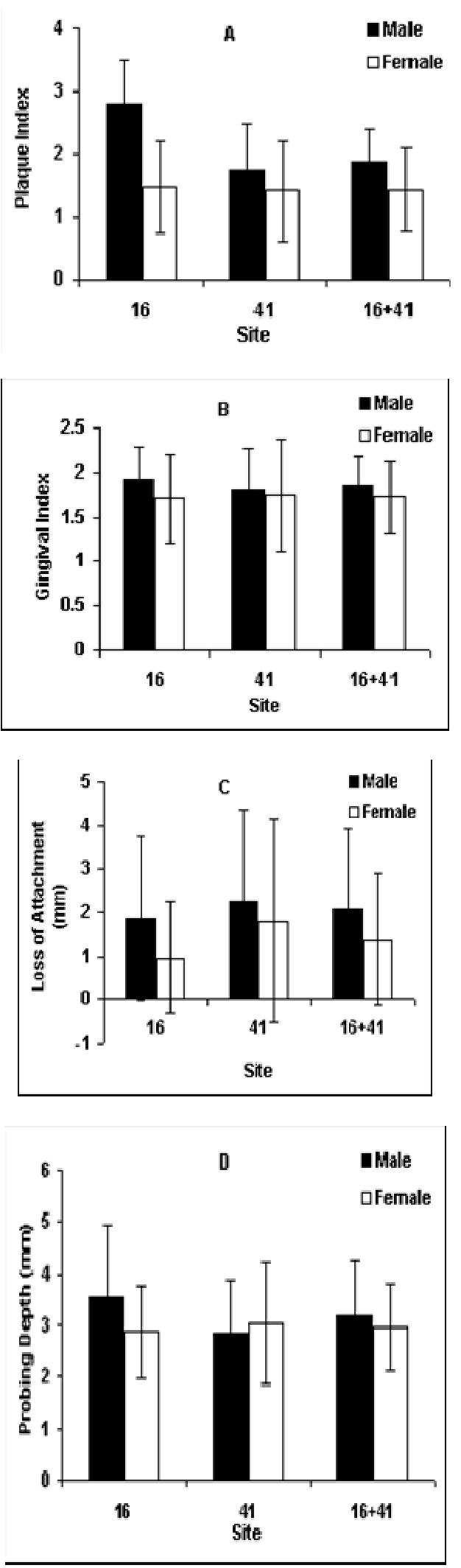

Figure 1. Mean (SD) for Plaque index (A), Gingival Index (B), Loss of Attachment (C), and Probing Depth (D) in Males and Females.

Comparison of clinical indices with age revealed significant correlations (Table 2). 
Table 2 .Comparison of Clinical Indices with Age.

\begin{tabular}{ll}
\hline Clinical Index & $\mathbf{1 \% \text { level of significance }}$ \\
\hline Plaque Index & $\mathrm{p}<0.001$ \\
Gingival Index & $\mathrm{p}=0.001$ \\
Loss of Attachment & $\mathrm{p}<0.001$ \\
Probing Depth & $\mathrm{p}<0.001$ \\
\hline
\end{tabular}

When the gender variable was introduced and the clinical indices were compared after grouping into 4 age groups, viz. 15-25 years, 26-35 years, 36-49 years and $>49$ years, significant differences were only observed for GI scores in the 26-35 and $>49$ age groups, and for LA in the 15-25 year age group (Figure 2 and Table 3 ).
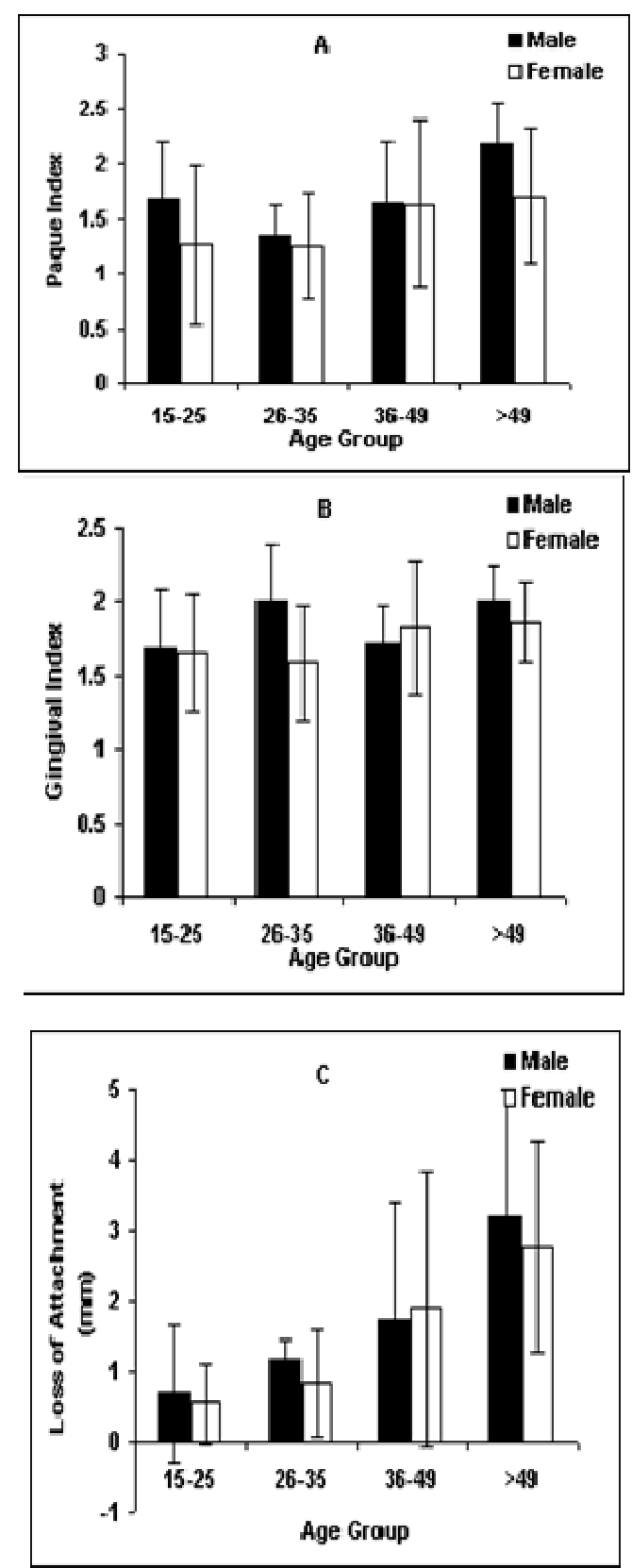

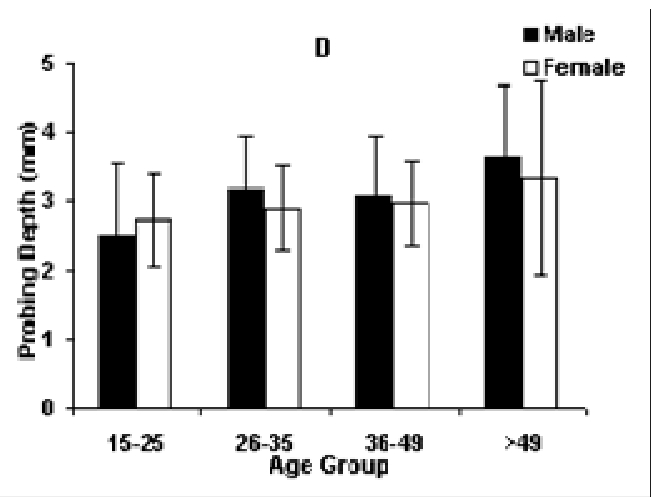

Figure 2. Breakdownof age and gender in study group.Comparisonof clinical indices.

Table 3. Comparing Gender Within Age Groups.

\begin{tabular}{|c|c|c|c|c|}
\hline \multirow[t]{2}{*}{ Clinical Index } & \multicolumn{4}{|c|}{ Distribution of Age Group in Years } \\
\hline & $15-25$ & $26-35$ & $36-49$ & $>49$ \\
\hline \multirow{3}{*}{$\begin{array}{l}\text { Males (n) } \\
\text { Females (n) }\end{array}$} & 12 & 3 & 7 & 18 \\
\hline & & & & \\
\hline & 31 & 40 & 35 & 22 \\
\hline Plaque Index & $\mathrm{p}=0.083$ & $p=0.179$ & $\mathrm{p}=0.176$ & $\mathrm{p}=0.073$ \\
\hline GingivalIndex & $\mathrm{p}=0.779$ & $\mathrm{p}=0.008^{*}$ & $\mathrm{p}=0.161$ & $\mathrm{p}=0.039 *$ \\
\hline $\begin{array}{l}\text { Loss of } \\
\text { Attachment }\end{array}$ & $\mathrm{p}=0.031^{*}$ & $\mathrm{p}=0.085$ & $\mathrm{p}=0.757$ & $\mathrm{p}=0.214$ \\
\hline Probing Depth & $\mathrm{p}=0.352$ & $\mathrm{p}=0.776$ & $\mathrm{p}=0.222$ & $\mathrm{p}=0.177$ \\
\hline
\end{tabular}

*Significant at 5\% level.

\section{Discussion}

Several studies have suggested associations between tooth loss and health outcomes such poor quality of life and mortality in older individuals. However, both dental caries and periodontal disease have been found to contribute to tooth loss at different ages, indicating a need for confounding risk factors to be identified.[40].Limited information is available associating gender with otherconfounding factors such as educational levels, oral hygiene practices and smoking status. In women, tooth loss has largely been associated with aging, menstruation, pregnancy, menopausal status, and living alone, while in men,tooth loss and higher periodontal scores have been associated with age, smoking and educational levels [41]Other studieshave found the above risk factors to be common in both genders[24],[42],[43] particularly in rural populations[25], [41].

This study examined the risk for tooth loss due to periodontal disease in a rural population in the remote town of Klipfontein near Cape Town, South Africa.They were selected for study because they reside in an area where the water supply has a high fluoride content, thus contributing to their protection against caries. This is an isolated com- 
munity who, until recently, were unexposed to the diet and habits of the western world. Previous studies [36],[37], [44] showed that this population had a low prevalence of caries and periodontal disease despite massive plaque accumulations.However, in interpreting the data, no direct comparison was made between males and females to establish whether gender would influence the risk for periodontal disease and tooth loss in this population.

Prevention of tooth loss due to early diagnosis of periodontitis has been advocated by many, withparticular attention being paid to 1 st molars and incisors [45].Molars and premolars are also reported to exhibit more rapid bone loss than incisors and canines [46] with more females losing their teeth because of dental caries and significantly more males $(p=0.001)$ losing their teeth because of periodontal disease [40]. In the present study, comparisons of males and females revealed that premolars (16) demonstrated higher PI, GI and PD scores than central incisors (41) in males only, with LA increased in " 41 " sites for both males and females. These differences were found to be statistically significant for GI and LA, suggesting a risk for tooth loss due to periodontal disease.

As demonstrated in the PI scores, females appeared to pay more attention to plaque control than the males resulting in better overall GI and LA scores. The reported method for tooth cleansing was a clean cloth, dipped in ash, followed by rinsing with water.Although using the same practice, the males were not as diligent, and all were heavy smokers which may have contributed to their poor oral health status.

In an earlier study, younger individuals with a reduced marginal bone level were reported to be at higher risk for further bone loss [46].Although similar results were reported in our study, the study by Bahrami et al. [46] did not investigate gender differences. Following a clinical examination during which the number of remaining teeth were recorded along with $\mathrm{PI}, \mathrm{GI}$, bleeding on probing (BOP), calculus index $(\mathrm{CI})$ and $\mathrm{PD} \geq 5 \mathrm{~mm}$, a significant difference between genders was reported $(p<0.05)$ with periodontal problems being the main reason for tooth loss [47] .In the present study, comparing genders within the different age groups demonstrated significant differences for GI in the 26-35 and $>49$ age groups (5\% level of significance) and for LA in the 15-25 age group. In the case of females, these differences may be attributed to hormonal changesdue to the use of oral contraceptives or menopause in the 36-49 and $>49$ age groups respectively [48].

Comparison of all the clinical indices with age showed that they were all highly significant (at the $1 \%$ level), thus the results of this study suggest that the risk for tooth loss due to periodontal disease in this community could be related to age rather than gender. A limitation of this study is the small number of males who participated.This was due to migrant labour. With most of the men working in neighbouring towns, we were able to recruit for this study only young males, the majority of whom had completed school- ing and were unable to find employment, and oldermen who, because of ill health or age discrimination, were also unemployed and therefore living in the hamlet at the time of this investigation.A more detailed longitudinal study with a better balanced gender profile will confirmthe identification of risk factors for tooth loss in this area.

\section{Acknowledgements}

The authors would like to thank the Klipfontein community for agreeing to participate in this study, Mr Claude Bayingana, Mr Elmalik Mohammed and Ms Tracy Arendse for data collection and analyses and Dr E Pool for preparing the Figures. This study was funded by the National Research Foundation. Any opinion, findings and conclusions or recommendations expressed in this material are those of the authors and therefore the NRF does not accept any liability in regard thereto.

\section{References}

[1] O'Mullane, D. , Whelton, H., Galvin, N."Health services and Women's oral health. "Journal of Dental Education. 57: 749-752. 1993.

[2] Eli I, Bar-Tal Y, Kostovetzki I.“AAt first glance: social meanings of dental appearance". Journal of Public Health Dentistry. 61(3):150-154.2001.

[3] Hyde S, Satariano W, Weintrub J. "Welfare dental intervention improves employment and quality of life."Journal ofDental Research. 85(1):79-84. 2006.

[4] Glied S and Neidell M."The economic value of teeth". Journal of Hum an Resources 45(2):468-496. 2010.

[5] Holmgren, C. J. , Corbet, E. F. , Lim, L P. ,"Periodontal conditions among middle-aged and the elderly in Hong Kong." Community Dentistry and Oral Epidemiology. 22(5): 396-402. 1994.

[6] Steele, J. G. , Walls, A. W. , Ayatollahi, S. M. , Murray, J. J. "Major clinical findings from a dental survey of elderly people in three different English communities."British Dental Journal. 180 (1): 17-23. 1996.

[7] Sanya, B. O. , Ng'ang'a, P. M. , Ng'ang'a, R. N. "Causes and pattern of missing permanent teeth among Kenyans."East African Medical Journal. 81(6): 322-325.2004.

[8] Angelillo IF, Nobile CG, Pavia M, DeFazio P, Puca M, Amati A."Dental health and treatment needs in institutionalised psychiatric patients in Italy."Community Dentistry andOral Epidemiology 23(6): 360-364. 1995.

[9] McCaul, L. K, Jenkins, W. M. , Kay, E. J. ,"The reasons for extraction of permanent teeth in Scotland: a 15-year followup study."British Dental Journal 190 (12): 658-662. 2001.

[10] Mack, F. , Mojon, P. , Budtz-Jorgensen, E. , Kocher, T. , Splieth, C. , Schwahn, C. , Bernhardt, O. et al. "Caries and periodontal disease of the elderly in Pomerania, Germany: results of the study of Health in Pomerania."Gerontology. 21: $27-36.2004$. 
[11] Ragnarsson, E. , Eliasson, S. T. , Olafsson, S. H. "Tobacco smoking, a factor in tooth loss in Reykjvik, Iceland."Scandinavian Journal of Dental Research. 100(6): 322-326. 1992.

[12] Norlen, P. , Johansson, I. , Birkhed, D."Impact of medical and lifestyle factors on number of teeth in 68-year-old men in Southern Sweden.”Acta Odontology Scandinavia. 54(1): 66-74. 1996.

[13] Xie, Q. , Ainamo, A. "Association of edentulousness with systemic factors in elderly people living at home." Соттиnity Dentistry and Oral Epidemiology. 27(3): 202-209. 1999.

[14] Hede B."Determinants of oral health in a group of Danish alcoholics. "European Journal of Oral Science. 104(4): 403-408. 1996

[15] Hu, C. Z, Huang, C. R, Rong, S. , Zhang, W. , Wu, J. , Pilot, T."Periodontal conditions in elderly people of Shanghai, People's Republic of China in 1986."Community DentalHealth 7(1): 69-71. 1990.

[16] Aleksejuniene J, Holst D, Eriksen M."Patterns of dental caries and treatment experience in elderly Lithuanians".Gerontology 17(2): 77-86. 2000.

[17] Shimazaki, Y. , Soh, I. , Saito, T. , Yamashita, Y. , Koga, T. , Miyazaki, H. , Takehara, T."Influence of dentition status on physical disability, mental impairment, and mortality in institutionalised elderly people."Journal of Dental Research. 80(12): 2042. 2001.

[18] Hiidenkari T, Parvinen T, Helenius H. "Edentulousness and its rehabilitation over a 10 -year period in a Finish urban area."Community Dentistry and Oral Epidemiology 25(5): 367-370. 1997.

[19] Sadig, W. M. , Idowu, A. T. "Removable partial denture design: a study of a selected population in Saudia Arabia."Contemporary Dental Practice 3(4): 40-53. 2002.

[20] Kalsbeek, H. , Truin, G. J. , Burgersdijk, R., van’t Hof, M. "Tooth loss and dental caries in Dutch adults."Community Dentistry and Oral Epidemiology. 19(4): 201-204. 1991.

[21] Weintraub, J. A. and Burt, B. A." Oral health status in the United States, tooth loss and edentulism."Journal of Dental Education 49(6): 368-378. 1985.

[22] Esan TA, Olusile AO, Akeredolu PA, Esan AO."Sociodemographic factors and edentulism: the Nigerian experience. BMC Oral Health. 4: 3 .2004.

[23] Shah, N. "Gender issues and oral health inelderly Indians."International DentalJournal. 53(6): 475-484.2003.

[24] Nalcaci, R, Erdemir, E. O.Baran, I. "Evaluation of the oral health status of the people aged 65 years and over living in near rural district of Middle Anatolia, Turkey."Archives ofGerontologyGeriatric. 45(1):55-64. Jul-Aug. 2007.

[25] Cheng, R. B. , Zhang, Y. , Cheng, M. , Li, Y. , Liu, L. "A sampled investigation on tooth loss of middle-aged and elders in Northeast China. "Shanghai Kou Qiang Yi Xue. 18(1):29-34.Feb. 2009.

[26] Ansai, T. Takata, Y. Soh, I. , Awano, S. Yoshida, A.Sonoki, K. Hamasaki, T. , Torisu, T. , Sogame, A. , Shimada, N. , Takehara, T. "Relationship between tooth loss and mortality in 80-year-old Japanese community-dwelling sub-
jects".BMC Public Health. DOI: 10.1186/1471-2458-10386.2010 .

[27] Simunkovic, S. K. , Boras, V. V. , Panduric, J. , Zilic, A. "Oral health among institutionalised elderly in Zagreb, Croatia."Gerontology. 22: 238-241. 2005.

[28] Suominen-Taipale, A. L. , Alanen, P. , Helenius, H. , Nordblad, A. , Uutla, A. "Edentulism among Finish."Community Dentistry and Oral Epidemiology. 27: 353-365.1999.

[29] Kawamoto, A. , Sugano, N. , Motohashi, M. , Matsumoto, S. , Ito, K. "Relationship between oral malodor and the menstrual cycle." Journal of Periodontal Research. 45(5):681-7.Oct. 2010.

[30] Beck JD, Pankow J, Tyroler HA et al. "Periodontitis: A risk factor for coronary heart disease? "Annals of Periodontology 3(1): 127-141. 1998.

[31] Beck JD, Elter JR, Heiss G et al. "Relationship of periodontal disease to carotid artery intima-media wall thickness: The atherosclerosis risk in communities (ARIC) study."Arteriosclerosis, Thrombosis and Vascular Biology. 21(11): 1816-1822.2001.

[32] Grau AJ, Buggle F, Ziedler C et al. "Association between acute and cerebrovascular ischemia and chronic and recurrent infection. Stroke 28: 1721-1729. 1997.

[33] Grossi SG and Genco RJ. "Periodontal disease and diabetes mellitus: A two-way relationship." Annals of Periodontology 3(1): 51-61. 1998.

[34] Jeffcoat, M. K, Geurs, N. C. , Reddy, M. S. , Goldenberg, R.I., Hauth, J.C. "Current evidence regarding periodontal disease as a risk factor in preterm birth."Annalsof Periodontology 6(1): 183-188.2001.

[35] Offenbacher S, Katz V, Fertik G, Collins J et al.'Periodontal infectionas a possible risk factor for preterm low birth weight."Journal of Periodontology. 67: 1103-1113. 1996.

[36] Africa, C. W. , Parker, J. R. , and Reddy, J. "Bacteriological studies of subgingival plaque in a periodontitis-resistant population. I. Darkfield microscopic studies."Journal of Periodontal Research, 20: 1-7.1985.

[37] Reddy, J. , Parker, J. R. , Africa, C. W. , Stephen, L. X. "Prevalence and severity of periodontitis in a high fluoride area in South Africa. " Community Dentistry and Oral Epidemiology. 13(2): 108-12. 1985.

[38] Silness, P. and Löe, H. "Periodontal disease in pregnancy II. Correlation between oral hygiene and periodontal conditions."Acta Odontology Scandinavia.22: 121-124. 1964.

[39] Löe, H. and Silness, J. “ Periodontal disease in pregnancy. Prevalence and severity."Acta Odontol Scandinavia 21: 551-553.1963.

[40] Shigli, K. , Hebbal, M. Angadi,, G. S. "Relative contribution of caries and periodontal disease in adult tooth loss among patients reporting to the Institute of Dental Sciences, Belgaum, India."Gerontology 26(3): 214-218. 2009.

[41] Wang, Q. T. , Wu, Z. F. et al. "Epidemiology and preventive direction of periodontology in China." Journal of Clinical Periodontology. 34(11): 946-951.2007.

[42] Musacchio, E. , Perissinotto, E. , Binotto, P. , Sartori, L. , 
Silva-Netto, F. , Zambon, S. , Manzato, E. , Corti, M. C. , Baggio, G. , Crepaldi, G. "Tooth loss in the elderly and its association with nutritional status, socio-economic and lifestyle factors."Acta Odontology Scandinavia 65(2): 78-86. 2007.

[43] Eickholz, P. , Kaltschmitt, J. , Berbig, J. , Reitmeir, P. , Pretzl, B. "Tooth loss after active periodontal therapy. 1: patient-related factors for risk, prognosis, and quality of outcome. "Journal of Clinical Periodontology. 35(2): 165-74. 2008 .

[44] Reddy, J., Van Wyk, C. W. , Groble, r S. "Epidemiology of dental caries and periodontal disease in a low and high fluoride area in South West Cape."Journal of the Dental Association of South Africa. 34: 703-705.1979.

[45] Savage, K. O., Ayanbadejo, P. O. "Pattern of tooth mobility and missing teeth types among juvenile periodontitis patients in Lagos University Teaching Hospital Dental Centre."Odontostomatol Trop 30(117); 11-5. 2007.

[46] Bahrami, G. , M. Vaeth, et al. "Marginal bone loss over 5 years in an adult Danish population."Oral Health Preventative Dentistry 5(2): 113-118.2007.

[47] Airila-Mansson, S. , Bjurshammar, N, Yakob, M., Soder, B. "Self-reported oral problems, compared with clinical assessment in an epidemiological study". International Journal Dental Hygiene. 5(2): 82-6. 2007.

[48] Haerian-Ardakani, A. , Moeintaghavi, A. et al. "The association between current low-dose oral contraceptive pills and periodontal health: a matched-case-control study." Journal of Contemporary Dental Practice 11(3): 033040.2010 . 